\title{
Enhancement of healthy and eco-friendly mining operations by adopting wet drilling method: An Innovative Approach
}

\author{
S.K.Maanju*Deepak Rawal* \\ *Vikram University,Ujjain(M.P.)India
}

\begin{abstract}
Drilling is an important operation of mining. Without drilling hardly any mine may be developed and worked. Drilling is such an operation which involved in creating pollution and health hazard. While dry drilling the cuttings of the stone along with fine dust is thrown out of the hole with air pressure and the driller remains directly close in touch and inhale this thrown out dust specially while drilling with jackhammer. Dry Jackhammer drilling also pollute the atmosphere with the evolution of dust in the air, containing silica particles and other crucial hard mineral particles which are dangerous for living existence. As such wet drilling can overcome the dust evolution and will suppress the dust and keep healthy inhalable atmospheric conditions.
\end{abstract}

Keyboard: - Jackhammer wet-drilling, protective nut, adaptor, nozzle etc.

\section{INTRODUCTION}

Most of mines producing building stone such as sandstone, Kota stone, marble, granite, silica-sand, asbestos, manganese, feldspar and quartz or any other hard minerals require constant jackhammer drillings. These stone mines are based on the silica contents of rocks. Therefore during dry drilling, the drillers are inhaling thrown out dust containing silica and also this dust pollutes the atmospheric air. The operators may suffer with Silicosis which is a chronic lung disease caused by inhaling silica dust. As such wet drilling can overcome the dust evolution and will suppress the dust and keep healthy inhalable atmospheric conditions.

\section{DRILLING SUGGESTED MODIFICATION}

Authors are proposing to develop a simple modified method of wet drilling with jackhammer. This method involves no expenditure and not much extra labor except only an understanding to keep an eco-friendly atmosphere at drilling operations. Authors propose simple modifications in the ordinary jackhammer as detailed below:

1. The top head protective nut and adapter has to be drilled hole of $1.5 \mathrm{~mm}$ through the top head.

2. The protective nut hole should be joined with $2 \mathrm{~mm}$ nozzle with gas welding as shown in fig. no. 1

3. In the adapter hole, pass a $1.5 \mathrm{~mm}$ steel hollow tube of $20 \mathrm{~cm}$. length and get it gas welded at the top around the side of the tube keeping the hole clear for passing water through it as shown in the fig no. 1

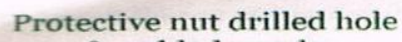


4. This welded adapter tube passing into the air flushing tube of length $37 \mathrm{~cm}$ nearly half of it's way keeping a clearance of $0.5 \mathrm{~mm}$ around it for the passage of air with force as shown in fig. no. 2

5. At nearly half of the way of the flushing air tube, air and water will join. At this junction point where air with force release from the narrow $0.5 \mathrm{~mm}$ clearance around of the water tube and join the tube water, carrying it to the flushing point through the drill rod hole with air force creating the vacuum at the junction point of water capillary tube and thus maintaining the continuous water flow with force. This is the principle of continuous water flowing and wet drilling as shown in fig. no. 2.

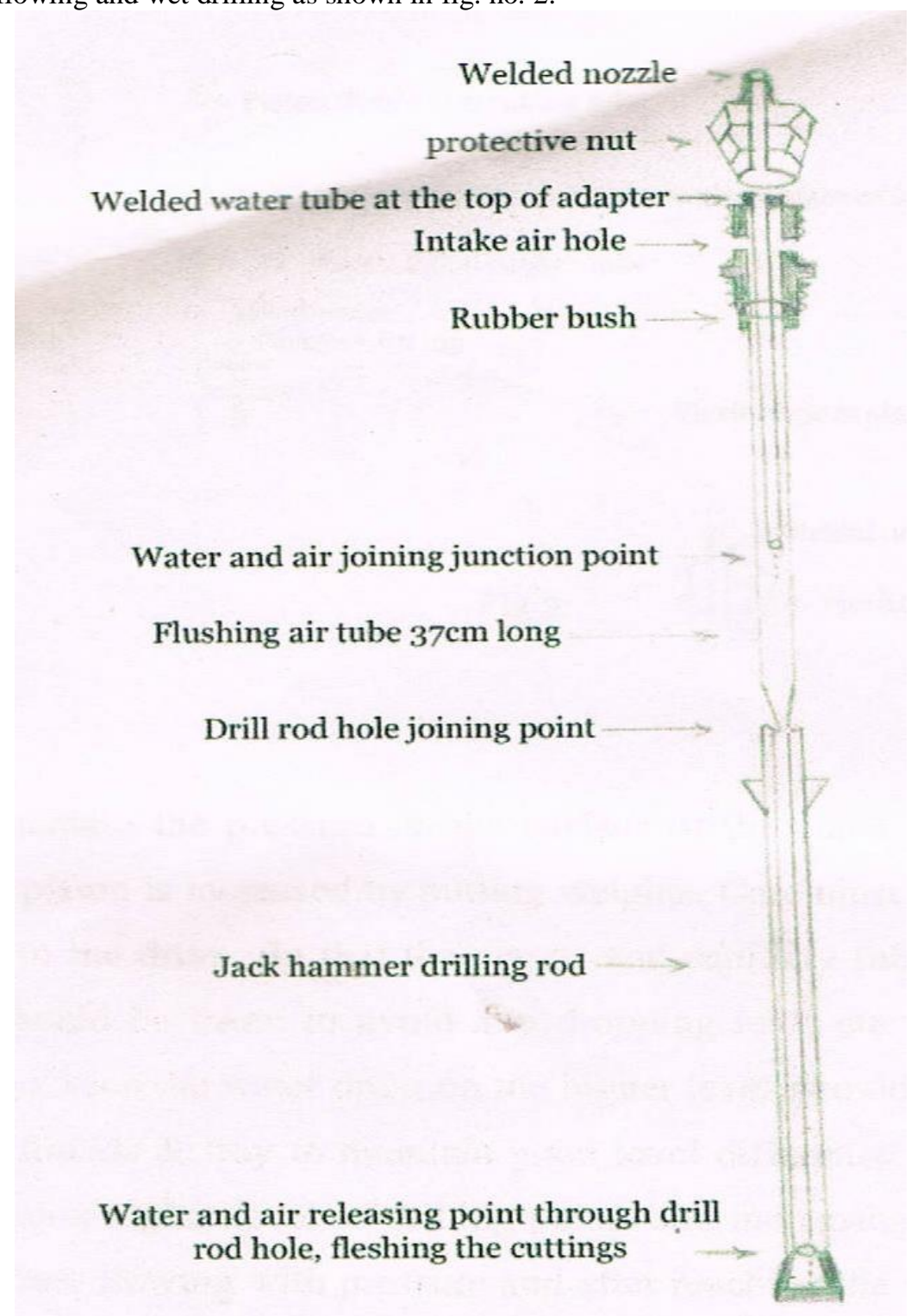

Fig. 2

6. For the supply of water continuously, very simple arrangements are needed. A plastic drum is taken as a water container and a $2 \mathrm{~mm}$ nozzle is connected at the bottom of the drum. A $5 \mathrm{~mm}$ plastic capillary flexible tube of $2 \mathrm{~mm}$ bore of good length of 100 meter is joined to the nozzle of the protective nut and nozzle of the drum. To maintain pressure on the surface of water to release water with force simple arrangements are needed. A small rubber tube of nearly water container drums diameter filled with air, let it be floated over the water surface of the drum. Then insert a hollow piston with covered bottom in the drum. The piston bottom will rest on the floating air tube which is to be floating on the surface of water in the water container drum as shown in the fig. no. 3 . 


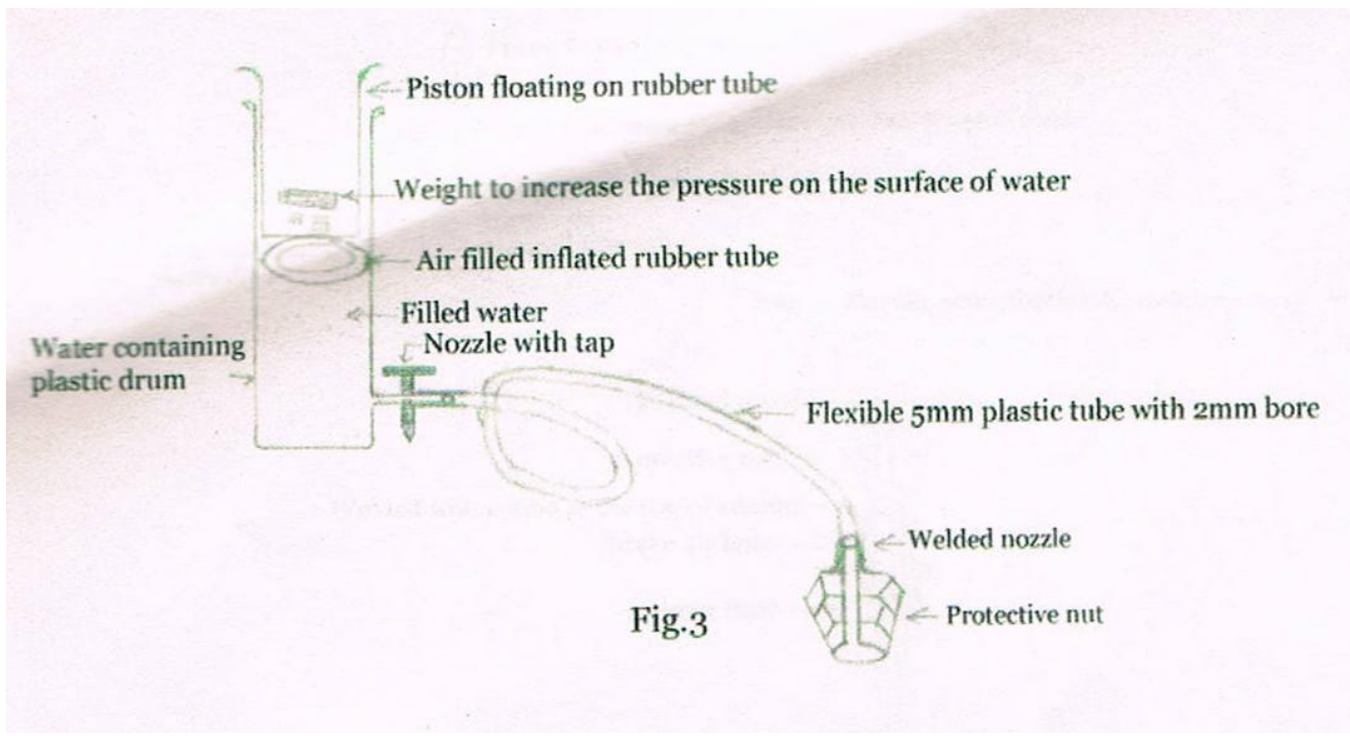

7. To increase the pressure on the surface of the water, the weight on the bottom cover of the piston can be increased by putting weights. Care must be taken to pour the water screened in to the drum so that the nozzle and capillary tube may not be choked and protection should be taken to avoid any dropping such as leafs etc. into the water container drum. Always keep the water drum on the higher level, providing level difference as per principle of liquids and try to maintain good level difference. These points keeping the water drum on a higher level of drilling points and increasing the weight on the piston, makes the water flowing with pressure and after reaching the water at the junction point in fleshing air tube, it will further drain with air force to the bottom of the hole at the drill cutting and flushing point and will create the vacuum at the junction point to maintain continuous flow of water as shown in fig $2 \& 3$.

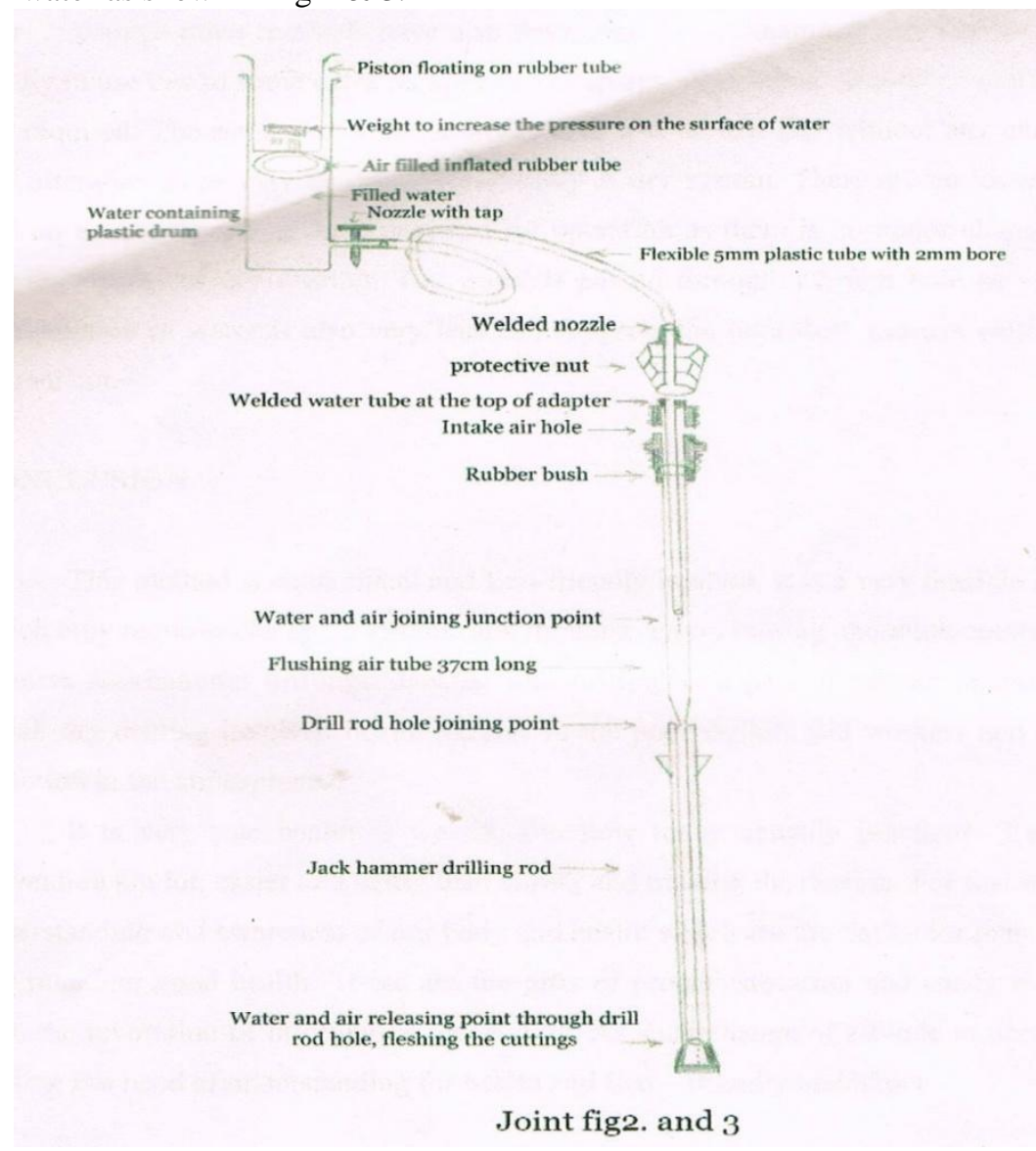




\section{RESULTS}

The drillers will easily and happily enjoy the wet drilling operations in a clean and healthy atmosphere. The one drum of water can be sufficient for 5 hours continuous drilling. Wet drilling have many meritorious advantages in addition to the suppressing of dust as under:

a) The rate of penetration can increase.

b) Life of the bit can increase.

c) Jamming of drilling roads can be eliminated.

d) It can give more length of drilling.

e) It can comply with safety rules and regulations 124(2).

f) It can reduce noise level.

g) It could be eco-friendly operation.

Though other methods are also available for jackhammer wet drilling but are hardly in use due to some extra requirement of spares. But in this proposed method no extra spares are required. The same jackhammer can work with wet system and without any change or any alteration same may be used continuously in dry system also. There will be no losses of air and no extra pressure of air will be required for operation as there is no suggestion in major change in its original spares of dry drilling. The water is suggested to be passed through $1.5 \mathrm{~mm}$ hole as such the consumption of water also appear very less.

\section{CONCLUSION}

This proposed method is economical and eco-friendly method. It is a very feasible method which only requires change in attitude and thinking. Every mining operation continuously requires jackhammer drillings. Jackhammer drilling is a part of mining operations in which dry drilling involved health hazards to the poor drillers and workers and created pollution in the atmosphere. As such change of attitude to accept proposed wet drilling is a need of hour for understanding good health and eco-friendly operations.

\section{REFERENCE}

[1] Arogyswami, R.N.P.(1980). Mining Geology. Oxford \& I.B.H. Pub. Co. New Delhi.

[2] Compell M.B. and T.H.Lehr (1974). Water Well Technology,Mc Graw Hill.

[3] Cummings J.D.(1956).Diamond Drilling Handbook,J.k.Smith and Sons,Canada.

[4] Indian Bureau of Mines (1950).Indian Mineral Exploration.. I.B.M.Press,Nagpur.

[5] Indian Bureau of Mines(1980). Exploration and Exploitation. I.B.M. Press, Nagpur.

[6] Keller,E.A.(1976). Environmental Geology. Charles E. Merrill pub. Co.Columbus,U.S.A.

[7] Lewis R.S. and G.B. Clark (1964),Element of Mining, John Wiley and Sons.

[8] Mc'Gregor K(1967).Drilling of Rocks,C.R. Books Ltd London.

[9] McKinstry. M.E.(1962).Mining Geology.Asia Pub.House, Bombay.

[10] Peel R.(1950) Mining Engineer`s Handbook, John Wiley and Sons.

[11] Peters, W.C. (1972). Exploration and Mining Geology. Asia Pub. House, Bombay.

[12] Statham I.C.F.(1963),Coal Mining Practice,Caxton Eastern Agencies.

[13] Sinha, R.K. and Sharma, N.L.( 1967). Mineral Economics, Allied Pub. Bombay.

[14] Thomas L.J.(1973) An Introduction to Mining, Hicks Smith and sons.

[15] Tarasov L. (1973), Mining Practice,MIR Publishers,Moscow.

[16] Young, G.S.(1951). Elements of Mining. Mc Graw Hill, New York, U.S.A.

[17] Zansam and Batman (1981). Mineral Deposits, John Wiley, New York, U.S.A. 